along the posterior border of the sterno-mastoid muscle. A large collection of pus was found on the anterior surface of the spinal canal, but not opening into it, the theca spinalis being whole. The left lateral half of the atlas was extensively necrosed and completely separated from the other portion (the dotted line in the diagram showing the separation), and could be easily removed by the fingers. The right half was represented by only small pieces of necrosed bone, both articulating facets of the occipital bone, and all those of the atlas, were also found to be necrosed; the transverse ligament of the atlas was absent.

It does not need any lengtby description or vivid portraiture to see what the effect of violent and sudden contraction of the sterno-mastoid muscles must be. The head would be drawn forwards, the transverse ligament being absent allows the odontoid process with the axis to slip backwards, crushing the medulla oblongata against the posterior part of the foramen magnum in this case, as there was little of the atlas left-ergo, instant death.

The treatment had been various, chiefly iodide of potassium at one time, quinine at another, now counterirritation to the nape of the neck, again sedative applications. The only medicine I gave him was quinine with gelseminum and a liniment composed of equal parts of cbloroform, tincture of opium, belladonna, and aconite, which he used freely, and expressed himself relieved by it, at least for a short time.

He had been seen and attended by several gentlemen, but the (apparently hidden) nature of the disease was, I think I am right in saying, never discovered during life. I thought the symptoms pointed either to aneurism of a basilar artery or abscess at the base of the brain.

Church, near Accrington.

\section{REPORT OF A CASE OF SEPTIC AEMIA.}

\section{By G. STANLEY MURRAY, M.D.}

SEEING some peculiar cases of septic poisoning recently reported in THE Lixcet, I submit the following, which occurred in my own practice, as being of special interest.

On the morning of the 30th of March a gentleman called at my house to see me, complaining of feeling unwell, though unable to point to any special ailment; describing his state as a general malaise, accompanied by weakness and debility. He was of rather a slight build, aged about twenty-seven, his complexion being dark and much tanned by exposure to the weather. He said he had recently returned from South America, where he had been living several years. His pulse was weak, and he seemed languid and somewhat depressed; complained of feeling drowsy and indisposed for exertion. He had a slight cough, but on ex. amining his chest I could detect nothing wrong. I put him on a mixture of ammonia, strychnia, and digitalis, desiring him to come and see me again in a day or two. On the 2 nd of April I was requested to visit him at his house. I found him in pretty much the same state, but complaining of headache, and saying his cough was becoming much more troublesome. His relatives, with whom he was staying, mentioned that he was restless, and they seemed to think he was really worse than he wished them to believe. Again examining his chest, I found slight crepitation in both lungs, accompanied by a hot dry skin. Fearing he was threatened with pneumonia I altered his medicine, and directed him to remain in bed, ordering hot fomentations and poultices to be constantly applied to the chest. On seeing him the following day, I found him decidedly worse, and learned that he had passed a restless night, that his cough had been very troublesome, the pain in the head more intense, and also that he had a slight attack of rigors during the night. On examination I found the chest symptoms now very marked. Making inquiries about his preceding history, I learned for the first time that some years ago he had gone to live in South America for the good of his health in consequence of a tendency to lung affection, where he seems to have led a very rough life, his principal occupation being cattle herding. His food largely consisted of dried beef, as hard and tough as boot leather, which he was obliged to grease and roll up in small quantities and swallow whole in consequence of his teeth being too bad to allow of his being able to masticate it Indeed, his return to England was solely in order, I believe, to have his teeth seen to, and the state of his mouth rectified before continuing his life in South America. I then learned that about three weeks before the time I first saw him he was taken up to one of the London hospitals by his brother (a student), and there put under ether, when eighteen stumps were removed by one of the house-surgeons. The next day he went agair and had three more taken out, and the following day one, making in all twenty-two teeth removed within three days. His mother told me that afterwards the state of his mouth was dreadful, and for days it was impossible to stay long in the room owing to the smell of his breath. This completely altered the aspect of the case, and left no doubt in my mind that I was dealing with a case of septic pneumonia.

I need not go into minute particulars, but only add that from day to day the patient gradually grew worse, signs of exhaustion setting in. Beef-tea, wine, raw eggs and milk were administered, and ammonia and bark prescribed, but without avail. On the 7th heavy sweating was manifested, and on the 9th his sleep began to leave him. After this the patient became dull and apathetic, only complaining of intense headache and thirst. On the 13 th he fell into a state of low delirium, and on the 15 th he died.

I cite the case as being one of interest, and as showing the effects of what may be considered a severe operation acting upon an enfeebled constitution.

Putney, S.W.

\section{A NEW CRADLE,}

SPECIALLY ADAPTED TO FIX EITHER TO A BACK-SPLINT OR TO THE LIMB, AS REQUIRED.

\section{BY WM. THOMAS JACKMAN, M.R.C.S., \&c.}

THESE small cradles will be found of great service to surgeons where it is desired to keep the bedclothes raised from an inflamed joint, either to avoid pressure or to increase the efficacy of evaporating lotions, by allowing above the limb a space into which evaporation can take place. They can be fixed securely to a back-splint, or to the limb if no splint is being used, by means of a broad strap of webbing;

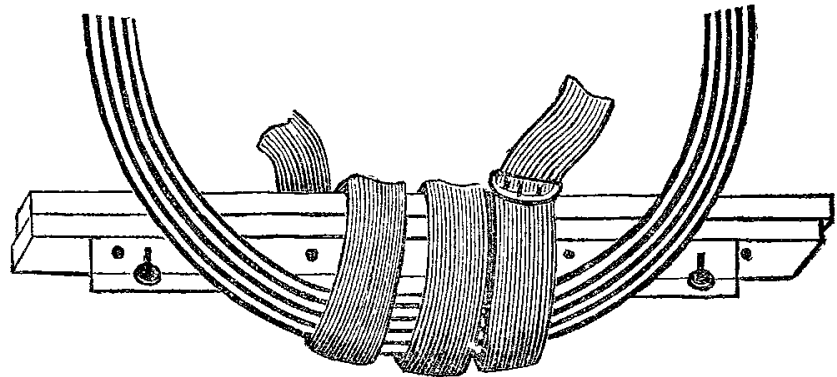

The cradle packed for carrying.

the space between the limb and the hoops of the cradle can be regulated as required. The cradles for the $\mathrm{knee}$ and ankle are made of wood, and consist of four movable cane hoops three inches and a half apart, capable of being fixed at any desired height over the limb into side bars of wood sixteen inches long. The cradle is further secured by means

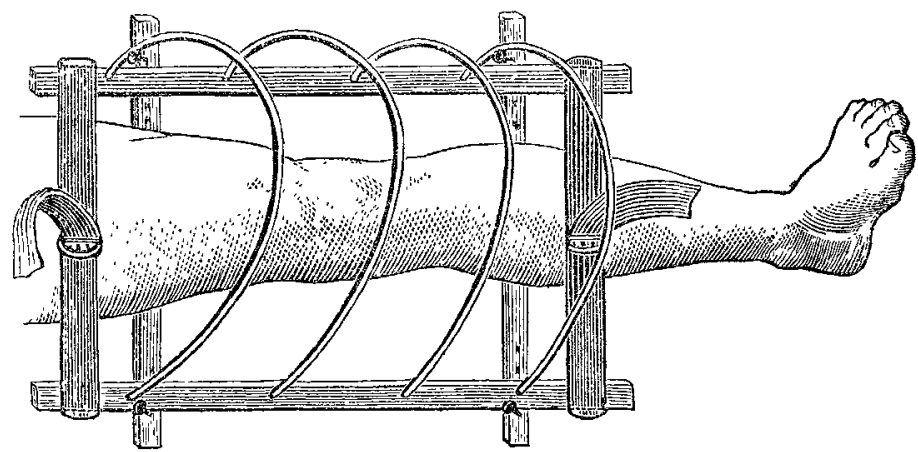

The cradle for the knee, adjusted.

of two sliding laths which pass under the limb and are fixed by pegs; these being adjusted, assist in the regulation of the height of the hoops. The whole apparatus is very portable, light, cleanly, and of easy adjustment. The length of the cradle is such that only the inflamed joint is 
protected from the clothes, thus avoiding discomfort to the patient, which the large cradles resting on the bed, as at present used, necessarily cause. The cradles, being really one with the splint or limb, can be conveniently used in cases where the limb is slung. The small space the cradle takes up in the bed is a great convenience. For the elbow-joint light angular cradles of stout iron-wire are more suitable; these are fixed to the splint or limb in the same manner as the wooden cradles. Messrs. Ferguson and Co., of Smithfield, are the makers.

Coggeshall, Essex

\section{d a diturror \\ OF}

\section{HOSPITAL PRACTICE, BRITISH AND FOREIGN.}

Nulla autem est alia pro certo noscendi via, nisi quamplurimas et morborum et dissectionum historias, tum aliorum tum proprias collectas habere, et inter se comparare.-Morgagri De Sed. et Caus. Morb., lib. iv. Procmium.

\section{ST. THOMAS'S HOSPITAL.}

OBSTRUCTION OF THE BOWELS; UMBILICAL HERNIA; PREGNANCY; RECOVERY.

(Under the care of Mr. SyDnEY JoNEs.)

M. A. S—_, female, aged thirty-six, married, was admitted on March 2nd, 1882, suffering from symptoms of obstruction of the bowels. The following history was obtained. She was about seven months gone in pregnancy, and during the whole of that time had suffered from sick. ness and anorexia; but on the evening of Feb. 26th she was attacked with violent diarrhœa and constant vomiting; she vomited about every ten minutes, and was unable to keep anything down. The diarrhoea ceased next morning, and from that time until her admission on March 2nd nothing had passed, although she had taken several doses of castor oil. She became very weak and prostrate, and the continued retching caused her much pain; the vomit was at first dark green, but on the day before admission became brownish in colour and very offensive. For the last five years she had had a swelling over the umbilicus, which she stated had never been reducible, but varied in size; it had not become larger of late, nor had it been more painful.

She was a very stout, florid woman, in a weak condition, with a temperature of $96.8^{\circ}$ and an extremely feeble pulse, and suffering from constant vomiting, the vomited matter consisting of a dark-brown, very offensive fluid. The abdomen was very large; there was a small umbilical hernia, but this did not present any evidence of strangulation beyond tenderness at the neck, and this was not more marked than the abdominal tenderness, which was generally diffused. There was a swelling in the lower part of the abdomen, evidently the pregnant uterus, the fotal heart being distinctly heard. Pulse 120, almost imperceptible at the wrist; tongue moist, furred. The patient suffered much from thirst. She was ordered one grain of opium pill at once, to be repeated every four hours; the vomiting stopped shortly after the first pill; she was able to keep down a little brandy and milk. About three o'clock she had a good deal of diarrhoea, the bowels acting five times before next morning.

On March 3rd she had not slept at all, but was feeling much relieved, and her pulse was much stronger, and there had been no further vomiting. On the $4 \mathrm{th}$ she vomited some greenish fluid in the evening. On the 6 th it was stated that she had had diarrhoea for the last twenty-four hours; no vomiting, but continual slight pain in epigastric region, worse before action of bowels; tongue moist, cleaning; pulse 86 , fair strength. Up to this date she had an occasional pill, none afterwards. On the 9th she left the hospital quite well, free ro $m$ pain ; no further vomiting or diarrhoea.

\section{WOLVERHAMPTON AND SOUTH STAFFORD- SHIRE HOSPITAL.}

SOME CASES OF EXCISION OF JOINTS.

(Under the care of Mr. VINCENT JACKsoN.)

CASE 1. Excision of Hip ; Recovery.-Henry T-, aged three, admitted May 10th, 1882, with hip disease. The joint was disorganised, and a large abscess had formed. On
June 1st the hip-joint was excised. The joint was exposed by a T-shaped incision. The head of the femur was found eroded, and the ligaments had ulcerated through in the front of the joint ; the acetabulum was healthy. The wound was washed out with chloride of zinc solution, and brought together by silk sutures, a drainage-tube being put in the most dependent part. Carbolic oil and absorbent wool. dressing were used, and the limb was fixed on an interrupted long splint. On the first evening after the operation the temperature was $102^{\circ}$, and up to the sixth day the evening temperature was close on $100^{\circ}$; after that it was normal. The wound took three months and a half to heal. The patient was discharged on Sept. 16th with an insignificant sinus; his general health was much improved by the opera. tion.

CASE 2. Excision of Hip; Recovery.-William Caged five, admitted on June 28th, 1882, had suffered from hip disease for a year. On July 13th the hip was excised in the same manner as in the previous case. The bone and cartilage of the head of the femur were carious, and the liga. ments pulpy. The wound healed well in two months. The temperature rose to $102^{\circ}$ on the third and fourth evenings, and kept a few points above normal for the first fortnight. Health continued good throughout.

CASE 3. Excision of Shoulder; Recovery.-James Waged thirty-six, was admitted on Nov, 23rd, with disease of the right shoulder. The joint had been diseased for over four months. An abscess had formed, and there were sinuses connected with the joint. On Jan. 18th the shoulder was excised. The joint was exposed by making a semicircular flap from the deltoid, and the head of the humerus removed below the trochanters. There was pretty sharp hæmorrhage, which was controlled by Spencer Wellsi forceps. A sequestrum as big as half-a-crown lay in the interior of the joint. The dead bone corresponded with a cavity at the back of the head of the humerus. The wound. edges were brought together with harelip pins, and a carbolic oil and wool dressing was used. On Feb. 26th the patient was discharged. There were then insignificant ulcerations in the cicatrix and a small sinus. A few weeks later the cicatrix was quite sound, and the patient was able to lift his hand to the back of his head. The patient being nervous in using his limb, it was some time before its motions were strong and vigorous. The temperature went up to $102 \cdot 8^{\circ}$ on the third evening; normal after the fourth day.

CASE 4. Excision of Shoulder; Recovery.-Alfred Faged eighteen. In January, 1881, the patient had rhellmatic fever, and from that period he dated the disease of his shoulder-joint. He was admitted on March 1st, 1882. He was then suffering from sinuses opening on the posterior margin of the deltoid. On March 23rd the shoulder was excised in the same manner as in the preceding case. The head of the humerus was carious. The wound healed well, and on April 20th the patient was discharged cured. Owing to the perseverance of the patient in moving his arm the limb soon became strong and useful.

CASE 5. Excision of Elbow; Recovery.-Francis N-. aged fifteen, had a compound backward dislocation of the elbow on July 21st, 1881. The dislocation was reduced under ether and dressed antiseptically. In August the joint was not doing well. It was soft and pulpy, and a sinus remained which communicated with dead bone. On August 18th Mr. Jackson excised the joint. The epiphyses of the humerus, radius, and ulna were necrosed. The limb was put on a splint for a week and then passive motion was used. The wound healed in a month and the patient was discharged on September 9th, 1881, with good movement at the elbow.

CASE 6. Excision of Elbow; Recovery.-Thomas Faged ten, was admitted on May 31st, 1882. He was a pale weakly little boy, badly nourished and poorly clad, but possessing excellent spirits. A trivial injury, his mother said, would cause an abscess. In February, 1879, he had knocked his right elbow. The joint became disorganised, and was excised by Mr. Jackson at that time. He now attended the hospital with disease of the left elbow, the result of injury. His health being improved by a good diet and a little wine Mr. Jackson excised the elbow on June 29th. The bones entering into the composition of the joint were carious, and the soft structures friable and pulpy. After the bones had been removed the diseased tissues were cut away with scissors or scraped with a Volkmann's spoon. The limb was put on a splint and kept wet with a spirit 